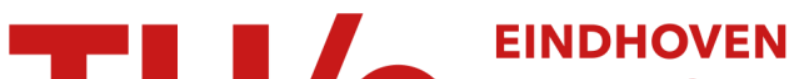 \\ UNIVERSITY OF \\ TECHNOLOGY
}

\section{Solid state diffusion and reactive phase formation}

\author{
Citation for published version (APA): \\ Loo, van, F. J. J., Rijnders, M. R., Rönkä, K. J., Gülpen, J. H., \& Kodentsov, A. (1997). Solid state diffusion and \\ reactive phase formation. Solid State Ionics, 95(1-2), 95-106. https://doi.org/10.1016/S0167-2738(96)00550-4
}

DOI:

10.1016/S0167-2738(96)00550-4

Document status and date:

Published: 01/01/1997

\section{Document Version:}

Publisher's PDF, also known as Version of Record (includes final page, issue and volume numbers)

\section{Please check the document version of this publication:}

- A submitted manuscript is the version of the article upon submission and before peer-review. There can be important differences between the submitted version and the official published version of record. People interested in the research are advised to contact the author for the final version of the publication, or visit the $\mathrm{DOI}$ to the publisher's website.

- The final author version and the galley proof are versions of the publication after peer review.

- The final published version features the final layout of the paper including the volume, issue and page numbers.

Link to publication

\section{General rights}

Copyright and moral rights for the publications made accessible in the public portal are retained by the authors and/or other copyright owners and it is a condition of accessing publications that users recognise and abide by the legal requirements associated with these rights.

- Users may download and print one copy of any publication from the public portal for the purpose of private study or research.

- You may not further distribute the material or use it for any profit-making activity or commercial gain

- You may freely distribute the URL identifying the publication in the public portal.

If the publication is distributed under the terms of Article 25fa of the Dutch Copyright Act, indicated by the "Taverne" license above, please follow below link for the End User Agreement:

www.tue.nl/taverne

Take down policy

If you believe that this document breaches copyright please contact us at:

openaccess@tue.nl

providing details and we will investigate your claim. 


\title{
Solid state diffusion and reactive phase formation
}

\author{
F.J.J. van Loo ${ }^{a}, *$, M.R. Rijnders ${ }^{a}$, K.J. Rönkä ${ }^{b}$, J.H. Gülpen ${ }^{a}$, A.A. Kodentsov ${ }^{a}$ \\ "Laboratory for Solid State Chemistry and Materials Science, Eindhoven University of Technology, P.O. Box 513, 5600 MB Eindhoven, \\ The Netherlands \\ ${ }^{\natural}$ Laboratory of Physical Metallurgy and Materials Science, Helsinki University of Technology, 02150 Espoo, Finland
}

\begin{abstract}
Thermodynamic and diffusion models were developed to describe the morphological evolution of the diffusion zone during interaction between inorganic materials. The application of these models is demonstrated for a number of metal/metal and $\mathrm{metal} /$ ceramic systems.
\end{abstract}

Keywords: Diffusion; Phase formation; Thermodynamics; Interfaces

\section{1. introduction}

Reactive phase formation during solid state diffusion is of concern in a wide variety of structures including composite materials and coatings, welded and bonded components, thin-film electronic devices and metallization. The stability of interfaces formed between inorganic materials is a problem of great technological importance. Since interdiffusion and chemical reactions at the interfaces affects the properties and performance of the multiphase structures, it is important to have a good understanding and control of the microchemistry of the interfacial region between dissimilar materials.

The chemical interaction at the interfaces is governed by the thermodynamics and reaction kinetics of the system under consideration. The former determines which phases are stable at the processing and service conditions and the latter determines how

\footnotetext{
${ }^{*}$ Corresponding author. Tel: (31-40) 247-3331; fax: (31-40) 244-5619; e-mail: tgtvmr@chem.tue.nl
}

much of a phase can be formed. If the thermodynamics (e.g., potential diagrams) and mobilities of all elements in all phases are known, the sequence, morphology and thickness of newly formed phases can be predicted to a large extent.

In efforts to describe the interfacial phenomena, two major obstacles arise. The first is that often no or only incomplete thermodynamic and diffusion data are available. The second is connected with problems in understanding the interrelations between the defect structure of materials, nucleation of new phases, mechanical stresses and morphological evolution of the reaction zone.

In the present work, use is made of equilibrium thermodynamics and diffusion kinetics in predicting the variation of chemical composition in the diffusion zone during solid state reactions between dissimilar materials. A number of metal/metal and metal/ceramic systems will be considered as examples. We assume that thermodynamic equilibrium is attained at the interfaces and that diffusion is the rate-limiting step, which means that all product 
layers in the reaction zone grow parabolically with time. Especially in the early part of the process this is not always true, and in thin-film experiments the interface concentrations do not always match the equilibrium phase diagram values because of surface energy effects. In this paper we will not go into these interesting aspects and just suppose a diffusion-governed process.

\section{Diffusion in a multiphase binary system}

If in a binary system the interdiffusion coefficient, $\tilde{D}$, is known as a function of temperature and concentration, the concentration profile across the diffusion zone can be calculated using relatively simple analyses, provided that equilibrium exists at the interfaces.

However, when intermetallic compounds with a very narrow region of homogeneity are formed during the solid state interaction, it is impossible to measure a concentration gradient for the components in these phases. It is, therefore, impossible to apply the conventional Matano-Boltzmann analysis to define interdiffusion coefficients for these phases. To avoid this problem the integrated diffusion coefficient, $D_{\text {int }}$, was introduced [1]. This coefficient, a materials constant, is defined for a phase $\alpha$ as the interdiffusion coefficient in $\alpha$, integrated over its (unknown) homogeneity limits $N^{\prime}$ and $N^{\prime \prime}$ :

$D_{\mathrm{int}}^{\alpha}=\int_{N^{\prime}}^{N^{\prime \prime}} \tilde{D}^{\alpha} \mathrm{d} N$.
This integrated diffusiun coefficient can be related to the parabolic growth constant of the phase $\alpha$ in a diffusion couple.

The formation of line compounds in the $\mathrm{Ni}-\mathrm{Si}$ system will be described as an example. It was demonstrated that the growth of $\mathrm{Ni}$-silicides in diffusion couples is diffusion controlled and that $\mathrm{Ni}$ is the most mobile species in the $\mathrm{Ni}_{5} \mathrm{Si}_{2}$ phase [2]. This means that the rate at which $\mathrm{Ni}_{5} \mathrm{Si}_{2}\left(=\mathrm{Ni}_{31} \mathrm{Si}_{12}\right.$ [3]) forms in the reaction zone is completely determined by the intrinsic diffusion coefficient of nickel in this phase. The tracer and the intrinsic diffusion coefficient, $D^{*}$ and $D$, respectively, are related through the thermodynamic factor [4]:

$D_{\mathrm{Ni}}=D_{\mathrm{Ni}}^{*}\left[1+\frac{\partial \ln \gamma_{\mathrm{Ni}}}{\partial \ln N_{\mathrm{Ni}}}\right]$,

where $\gamma$ is the activity coefficient. Eq. (2) can be substituted into Fick's first law and with $a=\gamma \cdot N$ the flux equation becomes:

$J_{\mathrm{Ni}}=-D_{\mathrm{Ni}}^{*} \frac{\partial C_{\mathrm{Ni}}}{\partial x}\left[\frac{\partial \ln a_{\mathrm{Ni}}}{\partial \ln N_{\mathrm{Ni}}}\right]$.

Considering a diffusion couple where $\mathrm{Ni}_{5} \mathrm{Si}_{2}$ is growing between $\mathrm{Ni}_{3} \mathrm{Si}\left(\mathrm{Ni}_{29} \mathrm{Si}_{9}\right.$ ) and $\delta-\mathrm{Ni}_{2} \mathrm{Si}$ (Fig. 1), one can use Eq. (3) to describe the flux of $\mathrm{Ni}$-atoms in $\mathrm{Ni}_{5} \mathrm{Si}_{2}$. If one assumes a constant molar volume, $V_{\mathrm{m}}$, and using $\mathrm{d} C_{\mathrm{Ni}}=\mathrm{d}\left(N_{\mathrm{Ni}} / V_{\mathrm{m}}\right)$ Eq. (3) can be integrated:

$J_{\mathrm{Ni}} \Delta X=D_{\mathrm{Ni}}^{*} \frac{N_{\mathrm{Ni}}}{V_{\mathrm{m}}}\left[\ln a_{\mathrm{Ni}}^{\mathrm{I}}-\ln a_{\mathrm{Ni}}^{\mathrm{II}}\right]$,

where superscripts I and II refer to the phase

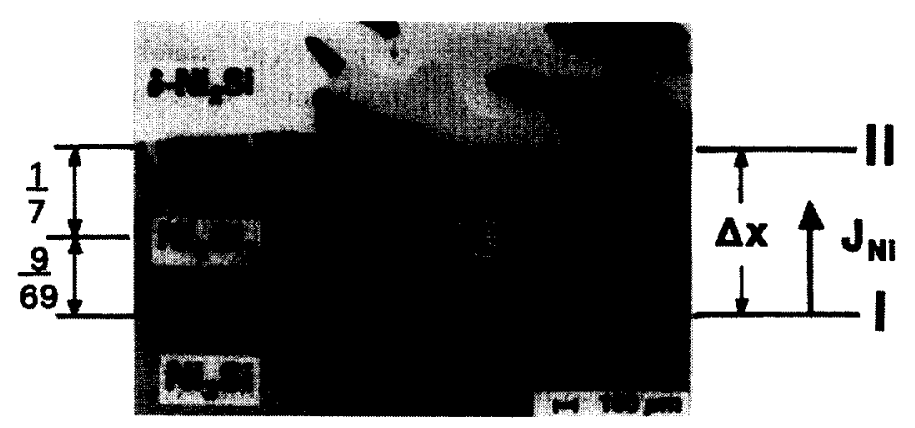

Fig. 1. Optical micrograph (polarized light) of a cross-section of a $8-\mathrm{Ni}_{2} \mathrm{Si} / \mathrm{Ni}_{3} \mathrm{Si}$ diffusion couple annealed at $1043 \mathrm{~K}$ in vacuum for $70 \mathrm{~h}$. Letter $\mathrm{K}$ indicates Kirkendall plane. 
boundaries $\mathrm{Ni}_{3} \mathrm{Si} / \mathrm{Ni}_{5} \mathrm{Si}_{2}$ and $\mathrm{Ni}_{5} \mathrm{Si}_{2} / \mathrm{Ni}_{2} \mathrm{Si}$, respectively. The following reactions take place:

$$
12 / 69 \mathrm{Ni}_{29} \mathrm{Si}_{9} \rightleftarrows 9 / 69 \mathrm{Ni}_{31} \mathrm{Si}_{12}+[\mathrm{Ni}]
$$

with $\Delta G^{\ominus}=-R T \ln a_{\mathrm{Ni}}^{1}$, and

$$
12 / 7 \mathrm{Ni}_{2} \mathrm{Si}+[\mathrm{Ni}] \rightleftarrows 1 / 7 \mathrm{Ni}_{31} \mathrm{Si}_{12}
$$

with $\Delta G^{\ominus}=+R T \ln a_{\mathrm{Ni}}^{\mathrm{II}}$.

Per one moving nickel atom $[\mathrm{Ni}]$ the net reaction is the sum of reaction $\mathrm{I}$ and II:

$$
\begin{gathered}
12 / 69 \mathrm{Ni}_{29} \mathrm{Si}_{9}+12 / 7 \mathrm{Ni}_{2} \mathrm{Si} \\
\rightleftarrows(9 / 69+1 / 7) \mathrm{Ni}_{31} \mathrm{Si}_{12}
\end{gathered}
$$

In Fig. 1 one can recognize the parts of the layer formed by reaction I and II; the different morphology reflects the different nucleation sites of the $\mathrm{Ni}_{5} \mathrm{Si}_{2}$ crystals at the interface I and II, respectively.

Eq. (4) can be written in terms of $\Delta_{\mathrm{r}} G^{\ominus}$ of the overall reaction (I+II) $\quad\left(=R T \ln a_{\mathrm{Ni}}^{\mathrm{II}}-R T \ln a_{\mathrm{Ni}}^{\mathrm{I}}\right)$. With $N_{\mathrm{Ni}}=31 / 43$ and $V_{\mathrm{m}}=1 / 43 V_{\mathrm{m}}\left(\mathrm{Ni}_{31} \mathrm{Si}_{12}\right)$ it becomes:

$J_{\mathrm{Ni}} \times \Delta x=-D_{\mathrm{Ni}}^{*} \frac{31}{V_{\mathrm{m}}\left(\mathrm{Ni}_{31} \mathrm{Si}_{12}\right)} \frac{\Delta_{\mathrm{r}} G_{\mathrm{Ni}}^{\ominus}}{R T}$,

where $\Delta_{\mathrm{r}} G_{\mathrm{Ni}}^{\ominus}$ is the standard Gibbs energy of the net reacting $\mathrm{Ni}$-atom, leading to $(9 / 69+1 / 7)=44 / 161$ mol $\mathrm{Ni}_{31} \mathrm{Si}_{12}$. The value of $\Delta_{\mathrm{r}} G_{\mathrm{Ni}}^{\ominus}$ can be easily visualized with the help of a plot as shown in Fig. 2 . The standard Gibbs energy of reaction per moving

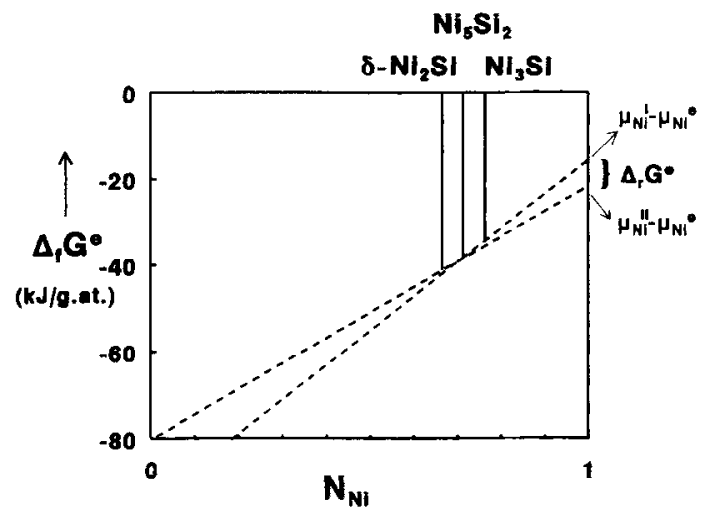

Fig. 2. Part of the stability diagram of the $\mathrm{Ni}-\mathrm{Si}$ system (based on thermodynamic data from [38]). $\Delta_{\mathrm{r}} G^{\ominus}$ is the Gibbs energy of reaction for the reaction (I+II).
$\mathrm{Ni}$-atom is equal to $\Delta \mu_{\mathrm{Ni}}$, which is the difference of the intersections of the common tangents with the axis $N_{\mathrm{Si}}=0$.

The growth of the $\mathrm{Ni}_{5} \mathrm{Si}_{2}$ layer between $\mathrm{Ni}_{3} \mathrm{Si}$ and $\mathrm{Ni}_{2} \mathrm{Si}$ can be described by the parabolic rate constant, $k_{\mathrm{p}}=\Delta x^{2} / 2 t$. Assuming nickel is the only diffusing element, one can write:

$\frac{\mathrm{d} x}{\mathrm{~d} t}=\frac{k_{\mathrm{p}}}{\Delta x}=\frac{44}{161} J_{\mathrm{Ni}} \times V_{\mathrm{m}}\left(\mathrm{Ni}_{31} \mathrm{Si}_{12}\right)$.

In fact, the growth rate is equal to the flux of $\mathrm{Ni}$-atoms, diffusing through the product layer, times the number of moles of $\mathrm{Ni}_{5} \mathrm{Si}_{2}$ formed by each mole of diffusing $\mathrm{Ni}$-atoms times the molar volume of $\mathrm{Ni}_{5} \mathrm{Si}_{2}$. Combining Eq. (5) and Eq. (6) gives:

$k_{\mathrm{p}}=\frac{31 \times 44}{161} D_{\mathrm{Ni}}^{*} \frac{\Delta_{\mathrm{r}} G_{\mathrm{Ni}}^{\ominus}}{R T}$.

Further, a relation between $k_{\mathrm{p}}$ and $D_{\text {inc }}$ can be derived [5], leading to:

$$
\begin{aligned}
D_{\mathrm{int}} & =-N_{\mathrm{Si}} D_{\mathrm{Ni}}^{*} \frac{N_{\mathrm{Ni}} \Delta_{\mathrm{r}} G_{\mathrm{Ni}}^{\ominus}}{R T} \\
& =\frac{12 \times 31}{43} D_{\mathrm{Ni}}^{*} \frac{\Delta_{\mathrm{r}} G_{\mathrm{Ni}}^{\ominus}}{R T} .
\end{aligned}
$$

The integrated diffusion coefficient is not dependent on starting materials in a diffusion couple as long as thermodynamic equilibrium is maintained at all interfaces. Eq. (8) gives a simple relation between integrated and tracer diffusion coefficient and $\Delta_{\mathrm{r}} G_{\mathrm{Ni}}^{\ominus}$. The ratio of the growth rates at the interfaces I and II (Fig. 1), which determines the position of the Kirkendall plane relative to the phase interface, is fixed by the reaction equation (I+II). Following the same analysis, it can be shown that for a stoichiometric phase growing between its neighbouring phases in which both elements are mobile:

$D_{\mathrm{int}}=-\left(N_{\mathrm{Si}} D_{\mathrm{Ni}}^{*}+N_{\mathrm{Ni}} D_{\mathrm{Si}}^{*}\right) \frac{N_{\mathrm{Ni}} \Delta_{\mathrm{r}} G_{\mathrm{Ni}}^{\ominus}}{R T}$.

It should be noted that the term $N_{\mathrm{Ni}}^{*} \Delta_{\mathrm{r}} G_{\mathrm{Ni}}^{\ominus}$ equals $N_{\mathrm{Si}}^{*} \Delta_{\mathrm{r}} G_{\mathrm{Si}}^{\ominus}$, with $\Delta_{\mathrm{r}} G_{\mathrm{Si}}^{\ominus}$ being the reaction free energy in the case of one $\mathrm{Si}$ atom moving from interface II to interface I (Fig. 1).

In order to describe quantitatively the transport of material in a growing phase one needs to know the 
contribution of the volume and the grain boundary diffusion to the diffusion coefficient. The effective diffusion coefficient, $D_{\text {eff }}^{*}$, which determines the growth rate, consists of the sum of the contribution of the two processes. In the $\delta-\mathrm{Ni}_{2} \mathrm{Si} / \mathrm{Ni}_{3} \mathrm{Si}$ diffusion couple the newly formed layer of $\mathrm{Ni}_{5} \mathrm{Si}_{2}$ exhibits a columnar morphology (Fig. 1). A simple model can be used to describe the overall transport of material during the growth process [6], the growing phase comprises two media, the lattice and grain boundaries. It forms two parallel diffusion paths with two different diffusivities $D_{\mathrm{v}}^{*}$ and $D_{\mathrm{GB}}^{*}$, leading to an effective diffusion coefficient $D_{\text {eff }}^{*}$. The experimental verification of this model can be found in [7].

\section{Diffusion in a ternary solid solution}

The composition of the diffusion zone in a ternary diffusion couple can be visualized by the so-called diffusion path (or reaction path). This is the locus of the average composition measured parallel to the original interface, which can be mapped on the isothermal Gibbs triangle of the system. Kirkaldy [3] and Clark [9] described a number of rules which have to be taken into account and they related the diffusion path to the set of four interdiffusion coefficients that can be determined in a ternary system, and which are a complex function of the mobilities of the components. However, one might gain more insight into the diffusion phenomena if one uses directly the mobilities or the tracer diffusion coefficients of the individual components. The following analysis gives an outline of the results which can be obtained.

In a thermodynamically ideal ternary solid solution a diffusion path is always $S$-shaped. If the mobilities of the elements in such a system are constant but different, the diffusion path can be predicted using a model of van Loo [10]. The starting direction of the diffusion path can be qualitatively estimated even without any calculations. If, for instance, in a couple $A B$ vs. $C$, the mobilities of atoms are in the sequence $D_{\mathrm{A}}>D_{\mathrm{B}}>D_{\mathrm{C}}$, then the diffusion path has to start from $A B$ in the $B$-richer direction. This determines, in principle, the $S$-shaped diffusion path [11].

In non-ideal solid solutions the prediction is more intricate as was demonstrated for the $\mathrm{Cu}-\mathrm{Fe}-\mathrm{Ni}$ system [12]. When the iso-activity curves and the mobilities of the elements are known it is possible to predict the diffusion paths in such systems as shown in the next analysis.

In a ternary system, Onsager's phenomenological diffusion coefficients form an $L(3 \times 3)$ matrix [13]. Assuming a vacancy mechanism for diffusion and neglecting correlation effects, it is possible to elimininate the non-diagonal elements in the $L_{i j}$ matrix. For the relation between phenomenological diffusion coefficients $L_{i j}$ and the tracer diffusion coefficient $D_{i}^{*}$, Darken has derived the equation [14]:

$L_{i i}=\frac{c_{i} D_{i}^{*}}{R T}$,

where $c_{i}$ is the concentration of component $i$ (mol cm ${ }^{-3}$ ). If the gradient of the chemical potential is the only driving force, the flux of atoms of component $i$ can be expressed as:

$J_{i}=-\frac{c_{i} D_{i}^{*}}{R T} \frac{\partial \mu_{i}}{\partial x}=-\frac{N_{i} D_{i}^{*}}{R T V_{\mathrm{m}}} \frac{\partial \mu_{i}}{\partial x}$,

where $N_{i}$ is the atomic fraction of component $i$ and $V_{\mathrm{m}}$ is the molar volume of the solid solution $\left[\mathrm{cm}^{3}\right.$ (mole of atoms) ${ }^{-1}$ ]. The chemical potential of each component is related to its thermodynamic activity through the equation:

$\mu_{i}=\mu_{i}^{0}+R T \ln a_{i}$

which leads to:

$J_{i}=-\frac{D_{i}^{*}}{V_{\mathrm{m}}} \frac{N_{i}}{a_{i}} \frac{\partial a_{i}}{\partial x}=-\frac{D_{i}^{*}}{V_{\mathrm{m}}} \frac{1}{\gamma_{i}} \frac{\partial a_{i}}{\partial x}$,

where $\gamma_{i}=a_{i} / N_{i}$ is the activity coefficient of component $\mathrm{i}$.

The relationship between the interdiffusion fluxes $\tilde{J}_{i}$ (defined with respect to the volume-fixed or Matana frame of reference) and the intrinsic fluxes $J_{i}$ (defined with respect to the lattice plane-fixed or Kirkendall frame of reference) is given by [10]:

$\tilde{J}_{i}=J_{i}-N_{i} \sum_{j=1}^{3} J_{j}$

Eq. (11) and Eq. (14) can be combined to: 


$$
\begin{aligned}
\tilde{J}_{1}= & -\frac{N_{1} D_{1}^{*}}{R T V_{\mathrm{m}}} \frac{\partial \mu_{1}}{\partial x} \\
& +N_{1}\left(\frac{N_{1} D_{1}^{*}}{R T V_{\mathrm{m}}} \frac{\partial \mu_{1}}{\partial x}+\frac{N_{2} D_{2}^{*}}{R T V_{\mathrm{m}}} \frac{\partial \mu_{2}}{\partial x}+\frac{N_{3} D_{3}^{*}}{R T V_{\mathrm{m}}} \frac{\partial \mu_{3}}{\partial x}\right) \\
\tilde{J}_{2}= & -\frac{N_{2} D_{2}^{*}}{R T V_{\mathrm{m}}} \frac{\partial \mu_{2}}{\partial x} \\
& +N_{2}\left(\frac{N_{1} D_{1}^{*}}{R T V_{\mathrm{m}}} \frac{\partial \mu_{1}}{\partial x}+\frac{N_{2} D_{2}^{*}}{R T V_{\mathrm{m}}} \frac{\partial \mu_{2}}{\partial x}+\frac{N_{3} D_{3}^{*}}{R T V_{\mathrm{m}}} \frac{\partial \mu_{3}}{\partial x}\right)
\end{aligned}
$$

$\tilde{J}_{3}=-\tilde{J}_{1}-\tilde{J}_{2}$.

Applying the Matano-Boltzmann analysis for multicomponent systems [15], the interdiffusion fluxes can be calculated from the experimental concentration profiles of two independent diffusion couples at the common composition $N_{i}^{\prime}$ :

$\tilde{J}_{i}=\frac{1}{2 t V_{\mathrm{m}}} \int_{N_{i}(-\infty)}^{N_{i}^{\prime}} x \mathrm{~d} N_{i}$

where the origin $(x=0)$ coincides with the Matanointerface.

Using thermodynamic data the experimental composition profiles can be converted into profiles of activity or chemical potential. At an intersection point of two independent diffusion profiles the three values for the interdiffusion fluxes in Eq. (16) can be obtained and the three tracer diffusion coefficients in Eq. (15) can be calculated. If one component has an extreme in its activity profile, one term in Eq. (15) can be neglected and two tracer diffusion coefficients can be calculated in this point from a single diffusion profile.

The vacancy flux can be calculated in a similar way:

$$
\begin{aligned}
J_{\mathrm{V}} & =-\int_{j=1}^{3} J_{j} \\
& =\frac{N_{1} D_{1}^{*}}{R T V_{\mathrm{m}}} \frac{\partial \mu_{1}}{\partial x}+\frac{N_{2} D_{2}^{*}}{R T V_{\mathrm{m}}} \frac{\partial \mu_{2}}{\partial x}+\frac{N_{3} D_{3}^{*}}{R T V_{\mathrm{m}}} \frac{\partial \mu_{3}}{\partial x} .
\end{aligned}
$$

At the original (Kirkendall) plane the vacancy flux is related to the 'marker shift' $\Delta x_{\mathrm{m}}$ by the relation:

$$
\frac{\Delta x_{\mathrm{m}}}{2 t}=V_{\mathrm{m}} J_{\mathrm{V}}
$$

and can, therefore, be measured independently. This allows the experimental verification of the model and especially of Eq. (17).

A number of ternary diffusion couples of the $\mathrm{Cu}-\mathrm{Fe}-\mathrm{Ni}$ system were annealed at $1273 \mathrm{~K}$ in vacuum. Composition of the couples and the experimentally determined diffusion paths are given in Fig. 3.

The thermodynamic calculations on the $\mathrm{Cu}-\mathrm{Fe}-\mathrm{Ni}$ system at $1273 \mathrm{~K}$ have been performed using primarily the critical assessment of Jansson [16]. On the hasis of our experimental results on equilibrated alloys, the ternary system has been reevaluated by introducing a new ternary parameter in the FCC phase which leads to a fair agreement between the calculated and experimental boundary of the miscibility gap in this system. The calculated miscibility gap is shown by a dashed line in Fig. 3 .

The tracer diffusion coefficients were calculated in the $\mathrm{Cu}-\mathrm{Fe}-\mathrm{Ni}$ system at $1273 \mathrm{~K}$ at the intersection points of two independent diffusion paths. They were consistent with the literature data in the binary $\mathrm{Cu}-$ $\mathrm{Ni}$ and $\mathrm{Fe}-\mathrm{Ni}$ systems as shown in Fig. 4 [17]. A good agreement was also found between the calculated and the independently (from the marker experiments) obtained values for the distance between the Kirkendall and Matano planes [12].

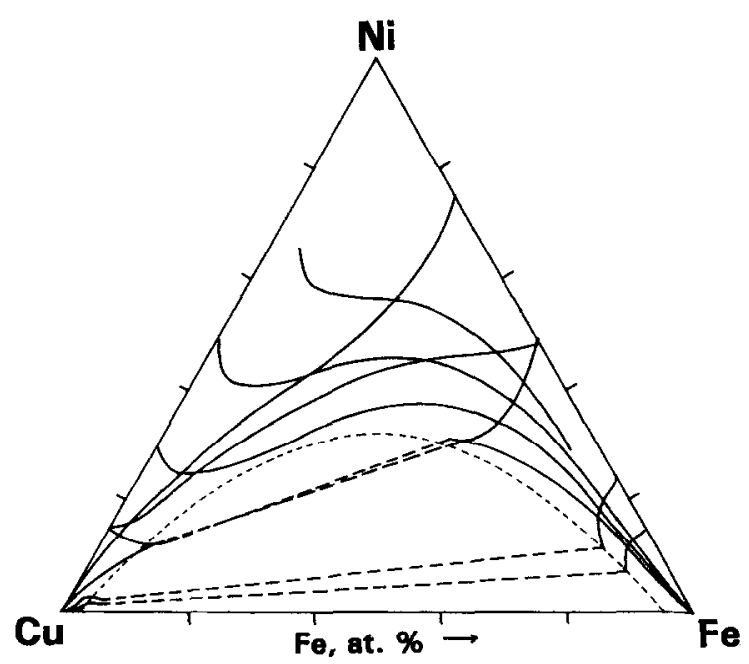

Fig. 3. The experimentally determined diffusion paths in the $\mathrm{Cu}-\mathrm{Fe}-\mathrm{Ni}$ system at $1273 \mathrm{~K}$. The calculated miscibility gap is shown by a dashed line. The diffusion paths inside the miscibility gap run parallel to the tie-lines. 


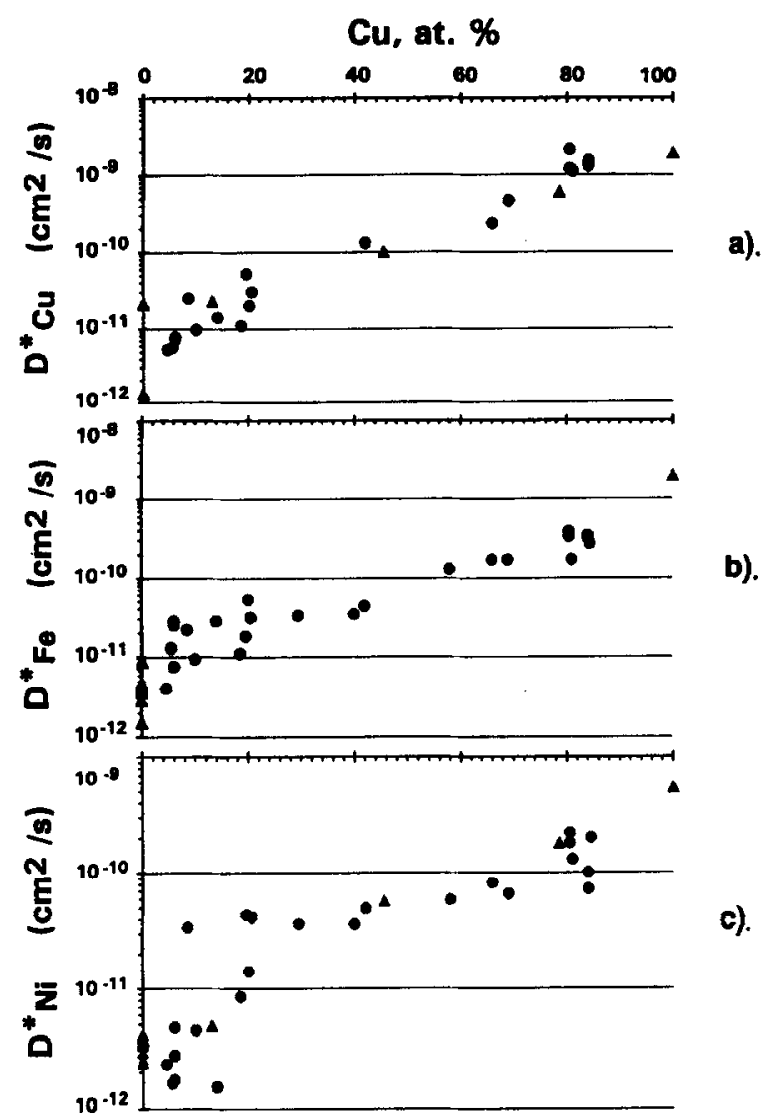

Fig. 4. The tracer diffusion coefficients of $\mathrm{Cu}(\mathrm{a}), \mathrm{Fe}(\mathrm{b})$ and $\mathrm{Ni}$ (c) (circles) at $1273 \mathrm{~K}$ as a function of the atomic fraction of copper calculated at the intersection points (Fig. 3). The literature data in binary $\mathrm{Cu}-\mathrm{Ni}$ and $\mathrm{Fe}-\mathrm{Ni}$ alloys [17] have been calculated from Arrhenius plots and are presented as triangles. The values in the binary $\mathrm{Fe}-\mathrm{Ni}$ system are shown on the axis $N_{\mathrm{Cu}} \rightarrow 0$. The highest values are in pure nickel and the lowest in pure iron.

The diffusion paths in the solid solution of a system with a miscibility gap are strongly influenced by the direction of the tie-lines as can be seen clearly from Fig. 3.

\section{Reactive phase formation in ternary systems}

Contrary to binary systems it is possible in a ternary system to develop two-phase areas in the diffusion zone because of the extra degree of freedom. The diffusion path reflects the morphology of the reaction zone. If phases are separated by planar interfaces, the diffusion path crosses the two-phase region parallel to a tie-line, as shown in Fig. 3 for four diffusion couples, and along the whole interface the same local equilibrium can be assumed. However, this is not necessarily the case: regions of supersaturation can be formed near the interfaces. This implies an interface which is thermodynamically unstable and gives rise to wavy interfaces or isolated precipitates. The diffusion path then crosses the tie-lines in the two-phase areas [8].

Rapp et al. [18] developed a simple model to predict the morphological evolution of the diffusion zone during solid-solid displacement reactions, based on the criterion of the limiting diffusion step in the product layers. Van Loo [19] added another guiding rule in addition to that, stating that the intrinsic diffusion of an element takes place only in a direction in which the chemical potential (activity) of that element decreases. Contrarily, interdiffusion fluxes can have the opposite direction. The utility of chemical potential diagrams in predicting the morphology of the reaction zone between ceramics and metals has been demonstrated in a number of systems $[20,21]$. We will restrict this discussion to the interaction between $\mathrm{SiO}_{2}$ and $\mathrm{Ti}$.

The isothermal cross-section through the ternary $\mathrm{Ti}-\mathrm{Si}-\mathrm{O}$ diagram at $1373 \mathrm{~K}$ was determined by combining a diffusion couple technique and the traditional methods of equilibrated alloys (Fig. 5a). However, from the isothermal cross-section through the phase diagram it is not unambiguously clear how the phase sequence in the reaction zone between $\mathrm{SiO}_{2}$ and $\mathrm{Ti}$ will be. For example, a diffusion path such as $\mathrm{SiO}_{2} / \mathrm{TiO}_{2} / \mathrm{Ti}_{4} \mathrm{O}_{7} / \mathrm{Ti}_{3} \mathrm{O}_{5} / \mathrm{Ti}_{2} \mathrm{O}_{3} / \mathrm{Ti}_{5} \mathrm{Si}_{3} / \beta$ $\mathrm{Ti}$ cannot be excluded when looking only at the phase equilibria in the $\mathrm{Ti}-\mathrm{Si}-\mathrm{O}$ system at $1373 \mathrm{~K}$. In principle, all these phases can form stable interfaces in such a hypothetical diffusion couple and the mass balance can be preserved. Activity (potential) diagrams can give more information for predicting the actual diffusion path. Such a diagram for $\mathrm{Si}$ is shown in Fig. 5b. The corresponding values for silicon activity were calculated using critically assessed values of $\Delta G^{\ominus}$ for the relevant binary systems. The same data were also applied to other systems, such as $\mathrm{Ti}-\mathrm{Al}-\mathrm{O}, \mathrm{Ti}-\mathrm{Si}-\mathrm{C}$ and $\mathrm{Ti}-\mathrm{Si}-\mathrm{N}[21,22]$. In all these cases the thermodynamically calculated diagrams were consistent with the experimental results. The possibility of the aforementioned diffusion path 

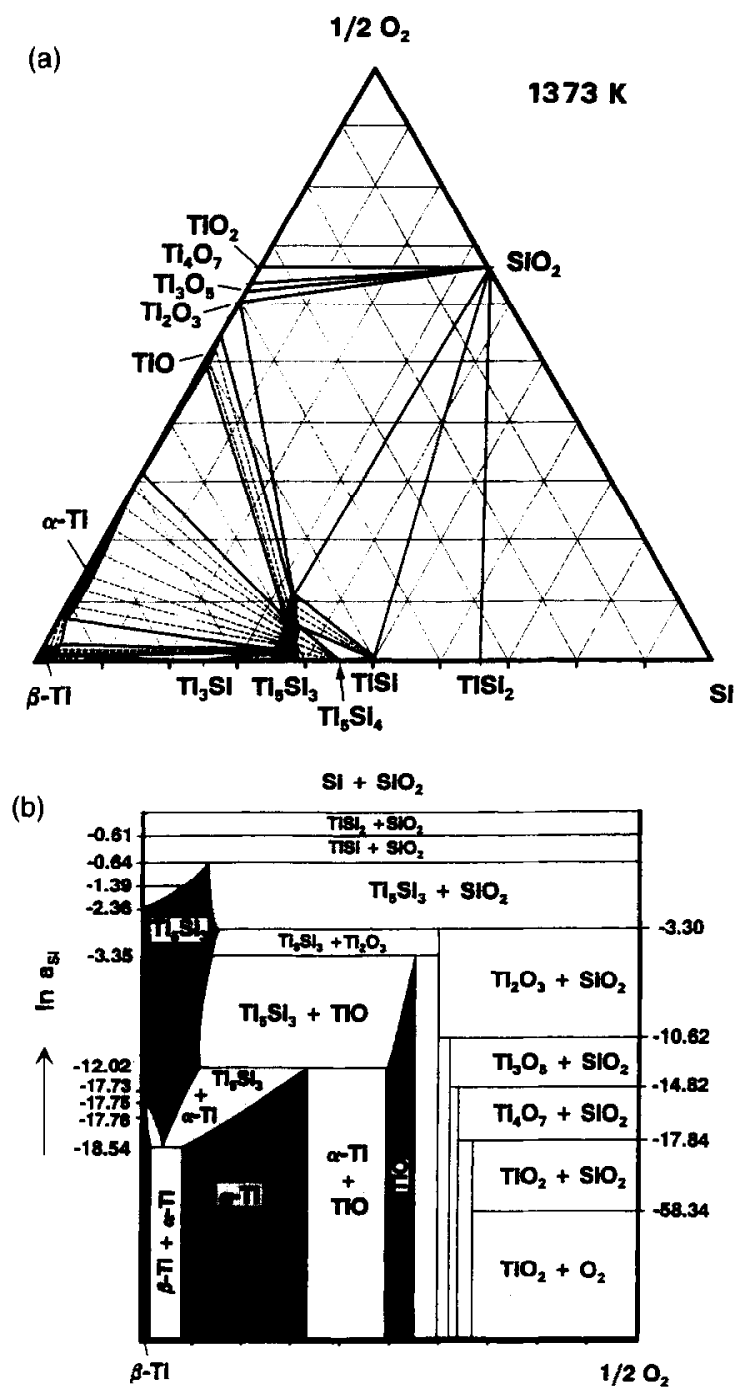

Fig. 5. (a) Experimentally determined isothermal cross-section through the $\mathrm{Ti}-\mathrm{Si}-\mathrm{O}$ phase diagram at $1373 \mathrm{~K}$; (b) corresponding potential (activity) diagram. Note the non-linear scale for the $\ln a_{5 i}$-axis.

can now be verified by superimposing this diffusion path on the potential diagram. It can be seen that $\ln a_{\mathrm{Si}}$ at the $\mathrm{SiO}_{2} / \mathrm{TiO}_{2}$ interface is $\leq-17.84$. This implies that the phase $\mathrm{Ti}_{5} \mathrm{Si}_{3}$ can never be formed, since the intrinsic diffusion of silicon should then take place towards a higher activity (the minimum value for $\ln a_{\mathrm{si}}=-3.35$, the equilibrium value for $\mathrm{Ti}_{2} \mathrm{O}_{3} / \mathrm{Ti}_{5} \mathrm{Si}_{3}$ coexistence\}, which is thermodynamically forbidden.

If the diffusion path would proceed further along the $\mathrm{Ti}-\mathrm{O}$ binary side until $\mathrm{TiO}$ before going to the phase field of $\mathrm{Ti}_{5} \mathrm{Si}_{3}$, then this would again be thermodynamically impossible, because the value of $\ln a_{\mathrm{Si}}$ at the $\mathrm{TiO} / \mathrm{Ti}_{5} \mathrm{Si}_{3}$ interface is $\geq-12.02$, which is higher than the maximum initial value of -17.84 . When the diffusion path goes further along the Ti-O binary side until $\alpha-\mathrm{Ti}$ is reached, then this path becomes thermodynamically possible but is kinetically not allowed because the mass balance cannot be maintained. Thus this model can predict which layer sequence is not allowed.

\section{Reactions in which a volatile product is formed}

If one considers the reaction between, e.g., $\mathrm{Si}_{3} \mathrm{~N}_{4}$ and a non-nitride forming metal, the product can be one or more metal silicides (or solid solution) plus nitrogen gas. This nitrogen gas has to disappear from the interface and it is clear that this poses some problems.

The type of reaction products which can be formed at elevated temperature, in the diffusion zone between $\mathrm{Si}_{3} \mathrm{~N}_{4}$ and any metal (or alloy), depends on the chemical potential (activity) of silicon and, hence, on the activity (fugacity) of nitrogen at the contact surface.

When using a porous $\mathrm{Si}_{3} \mathrm{~N}_{4}$ starting material or a powder mixture of a non-nitride forming metal and $\mathrm{Si}_{3} \mathrm{~N}_{4}$, the reaction products will entirely depend on the surrounding $\mathrm{N}_{2}$ partial pressure, because this pressure determines the activity of $\mathrm{Si}$ at the $\mathrm{Si}_{3} \mathrm{~N}_{4}$ interface. When using diffusion couples consisting of dense $\mathrm{Si}_{3} \mathrm{~N}_{4}$ and non-nitride forming metals, the interior of the couple is not in direct contact with the surrounding atmosphere. Nitrogen which is formed by the interfacial reaction cannot escape easily. A nitrogen pressure (fugacity) will be built up at the contact surface. It decreases the chemical potential of $\mathrm{Si}$ at the metal/ceramic interface, leading to reaction products which contain less silicon compared with porous couples.

As an example, the calculated stability diagram for the Mo-Si-N system is given in Fig. 6 [23]. This graph displays which solid phases of the system are in equilibrium with $\mathrm{Si}_{3} \mathrm{~N}_{4}$ as a function of temperature and partial pressure of nitrogen. The activity of 


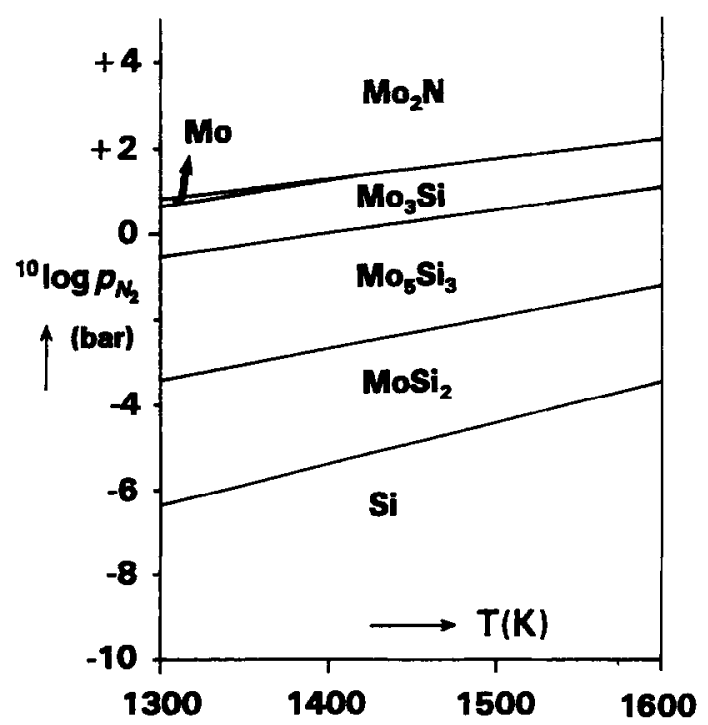

Fig. 6. Stability diagram showing solid phases in equilibrium with solid $\mathrm{Si}_{3} \mathrm{~N}_{4}$ in the $\mathrm{Mo}-\mathrm{Si}-\mathrm{N}$ system as a function of temperature and nitrogen partial pressure (fugacity).

silicon at the metal/ceramic interface is related to the $\mathrm{N}_{2}$ partial pressure (fugacity and hence activity) through the equilibrium constant of $\mathrm{Si}_{3} \mathrm{~N}_{4}$. Only $\mathrm{Mo}_{3} \mathrm{Si}$ was found in the reaction zone after diffusion bonding of dense $\mathrm{Si}_{3} \mathrm{~N}_{4}$ with $\mathrm{Mo}$ at $1573 \mathrm{~K}$ in vacuum, and no $\mathrm{Mo}_{2} \mathrm{~N}$ had been formed. According to calculations, it means that the nitrogen pressure at the interface can be estimated to be somewhere in between 10 and 100 bar.

This is corroborated by the diffusion couple experiments between $\mathrm{Mo}$ and $50 \%$ porous $\mathrm{Si}_{3} \mathrm{~N}_{4}$ (Fig. 7). Layers consisting of $\mathrm{MoSi}_{2}$ and $\mathrm{Mo}_{5} \mathrm{Si}_{3}$ are formed in the transition zone. Obviously, the whole Mo part of the couple has been consumed, as well as the $\mathrm{Mo}_{3} \mathrm{Si}$ layer which must have been present after shorter annealing times. It is clear that no $\mathrm{N}_{2}$ pressure can build up at the interface because $\mathrm{N}_{2}$ can escape through the open pores in the $\mathrm{Si}_{3} \mathrm{~N}_{4}$. It increases the chemical potential of $\mathrm{Si}$ at the contact surface resulting in the formation of Si-rich silicides. The same phases are found at the edges in couples with dense $\mathrm{Si}_{3} \mathrm{~N}_{4}$ where the contact interface meets the surrounding atmosphere (vacuum).

In the case of $\mathrm{Ni} / \mathrm{Si}_{3} \mathrm{~N}_{4}$ diffusion couples, no intermetallic compounds were detected after solid state bonding at $1398 \mathrm{~K}$ in vacuum or under hydro-

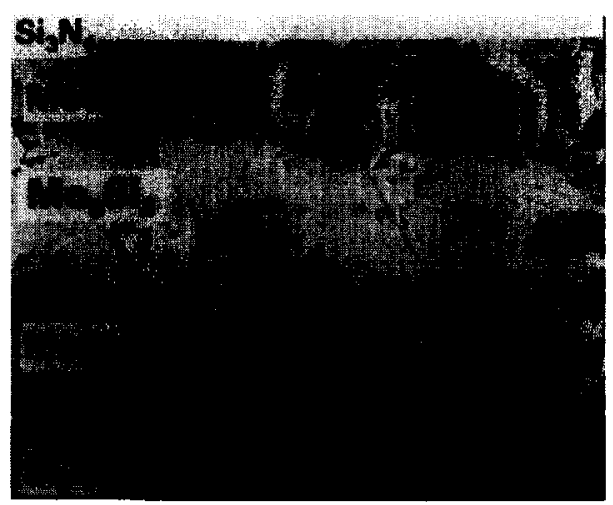

Fig. 7. Secondary electron image (SEI) of the reaction zone between $\mathrm{Mo}$ and $50 \%$ porous $\mathrm{Si}_{3} \mathrm{~N}_{4}$ annealed at $1573 \mathrm{~K}$ in vacuum for $50 \mathrm{~h}$.

gen-containing mixtures (Fig. 8). Only a Ni-Si solid solution with a maximum $\mathrm{Si}$ concentration of about 15 at.\% was formed, which according to the calculated stability diagram (Fig. 9) implies a nitrogen pressure (fugacity) at the contact surface $\geq 50$ bar.

A $\mathrm{N}_{2}$ pressure build-up at the metal ceramic interface is also proven experimentally by the morphology of the reaction zone after binding of silicon nitride with $\mathrm{Ni}-\mathrm{Cr}$ alloys at $1398 \mathrm{~K}$ [24]. As in diffusion couples with pure nickel, no silicides were formed in the transition zone. Numerous precipitates of cubic $\mathrm{CrN}$ inside the $\mathrm{FCC} \mathrm{Ni}-\mathrm{Cr}(\mathrm{Si})$ solid solution were detected by TEM (Fig. 10).

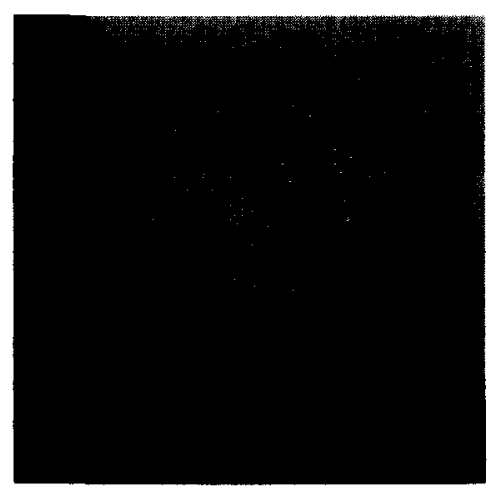

Fig. 8. Backscattered electron image (BEI) of the diffusion zone between dense $\mathrm{Si}_{3} \mathrm{~N}_{4}$ and $\mathrm{Ni}$ after annealing at $1398 \mathrm{~K}$ under 1 bar of a gas mixture $\mathrm{Ar}+10$ vol. $\% \mathrm{H}_{2}$ for $120 \mathrm{~h}$. The Kirkendall plane is indicated by $\mathrm{K}$. 


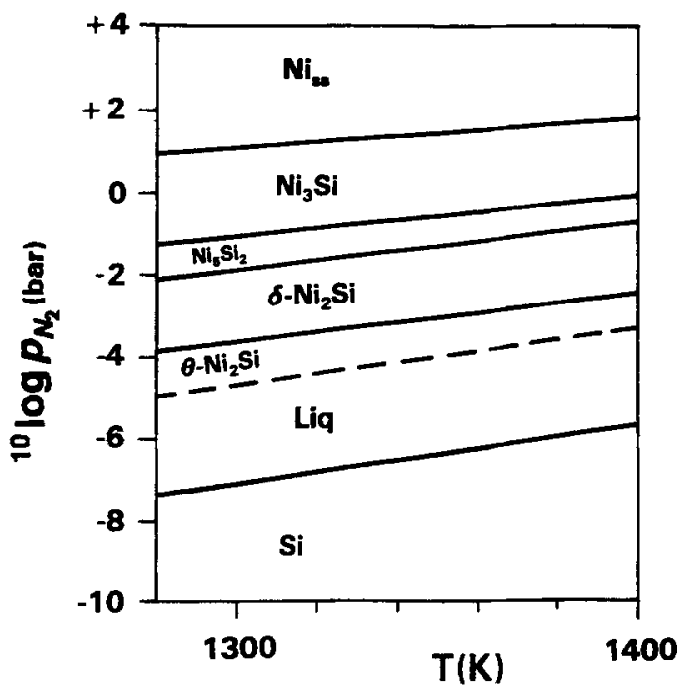

Fig. 9. Solid phases in equilibrium with solid $\mathrm{Si}_{3} \mathrm{~N}_{4}$ in the $\mathrm{Ni}-\mathrm{Si}-\mathrm{N}$ system as a function of temperature and nitrogen partial pressure.

The calculated and experimentally verified stability diagram of chromium nitrides at $1398 \mathrm{~K}$ in various $\mathrm{Ni}-\mathrm{Cr}$ alloys as a function of nitrogen fugacity is given in Fig. 11 [25]. In fact, with this graph it is possible to predict which nitride phase will be formed at the metal/gas interface under a certain pressure of nitrogen. The formation of cubic $\mathrm{CrN}$ inside the diffusion zone quite far from the metal/ceramic interface, underlines the high activity of nitrogen at the contact surface during the interaction of dense $\mathrm{Si}_{3} \mathrm{~N}_{4}$ with $\mathrm{Ni}-\mathrm{Cr}$ alloys. The presence of traces of oxygen in the ambient atmosphere may influcnce the reaction products, as discussed in [23].

\section{The formation of layers periodic in space and time}

A periodic layered morphology of the reaction zone has been observed in several annealed solid/ solid diffusion couples, both in metal/metal and metal/ceramic systems. This morphology is characterized either by a regular array of alternating single-phase layers or by bands of particles embedded in an intermetallic matrix phase.

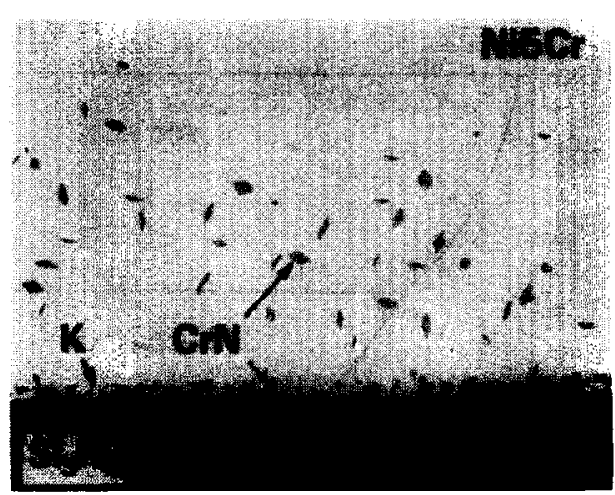

(a)

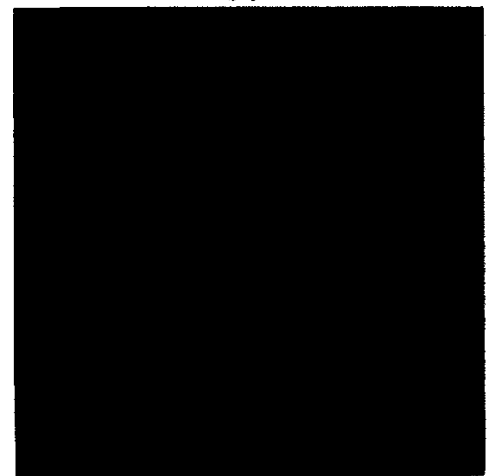

(b)

Fig. 10. (a) Microstructure (SEI) of a diffusion couple Ni (5 at.\% $\mathrm{Cr})+\mathrm{Si}_{3} \mathrm{~N}_{4}$ annealed for $32 \mathrm{~h}$ at $1398 \mathrm{~K}$ in vacuum. Kirkedall plane is indicated by $\mathrm{K}$; (b) selected area diffraction pattern taken from a nitride particle formed inside the reaction zone showing the [100] direction in the cubic lattice of $\mathrm{CrN}$.

\subsection{Periodic layer formation as a Liesegang phenomenon}

Fig. 12 shows the reaction zone in a $\mathrm{Ag} / \mathrm{Ti}$-foil $(15 \mu \mathrm{m}) / \mathrm{Si}$ 'sandwich' diffusion couple after annealing at $1023 \mathrm{~K}$ in vacuum for $720 \mathrm{~h}$. This structure is formed through reaction between binary reaction products of the $\mathrm{Ti}-\mathrm{Si}$ and $\mathrm{Ti}-\mathrm{Ag}$ systems, after the Ti-foil has been consumed. It consists of intermittent bands of pure silver embedded in a matrix of titanium silicide ( $\mathrm{TiSi}_{2}$ ).

As long as pure titanium is present in the transition zone, the growth of intermetallics is governed by the thermodynamics and diffusion kinetics of the respective binary systems, $\mathrm{Ti}-\mathrm{Si}$ and $\mathrm{Ti}-\mathrm{Ag}$. This means that all binary equilibrium intermetallics are 


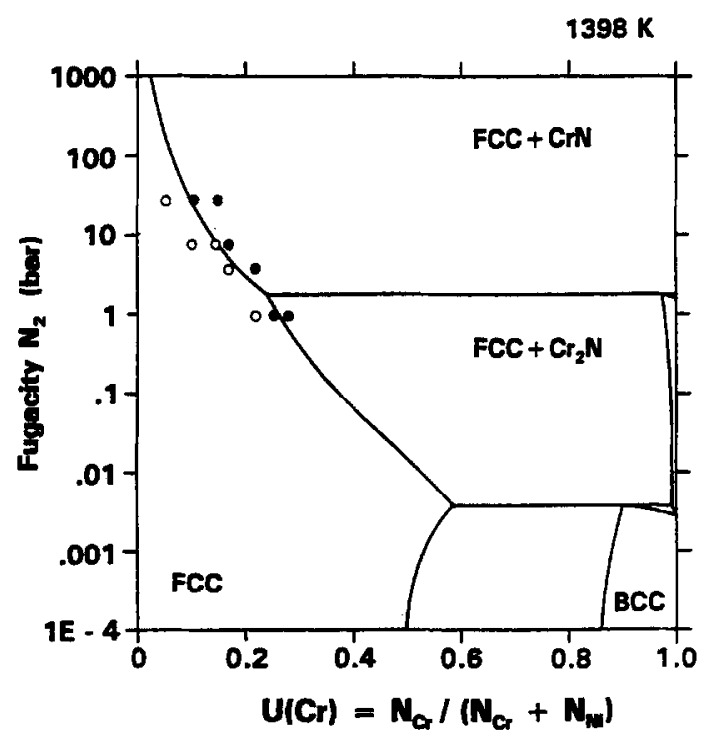

Fig. 11. Calculated stability diagram of chromium nitrides at 1398 $\mathrm{K}$ in various $\mathrm{Ni}-\mathrm{Cr}$ alloys as a function of nitrogen fugacity, together with experimental data chromium nitride was detected at the surface of alloy with XRD analysis; $O$ no nitride formation).

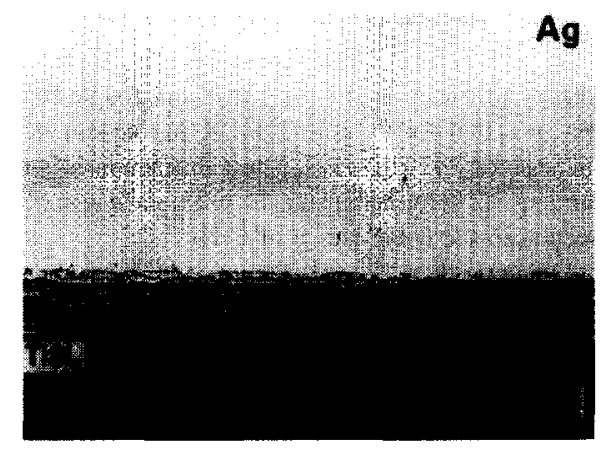

Fig. 12. Reaction zone morphology of a sandwich diffusion couple $\mathrm{Ag} / \mathrm{Ti}$-foil $(15 \mu \mathrm{m}) / \mathrm{Si}$ after annealing at $1023 \mathrm{~K}$ in vacuum for $720 \mathrm{~h}$ (BEI).

present inside the transition zone. The most titaniumrich intermetallic compounds of the respective binary systems, $\mathrm{Ti}_{3} \mathrm{Si}$ and $\mathrm{Ti}_{2} \mathrm{Ag}[26]$ will come into contact when the Ti-foil is completely consumed. The two semi-infinite binary couples have now been transformed to a finite ternary system. According to the experimentally determined phase diagram of the Ti$\mathrm{Ag}-\mathrm{Si}$ system [27], at $1023 \mathrm{~K} \mathrm{Ti}_{3} \mathrm{Si}$ and $\mathrm{Ti}_{2} \mathrm{Ag}$ are in equilibrium (Fig. 13). The reaction, however, proceeds because of the existing $\mathrm{Si}$ and $\mathrm{Ag}$ chemical

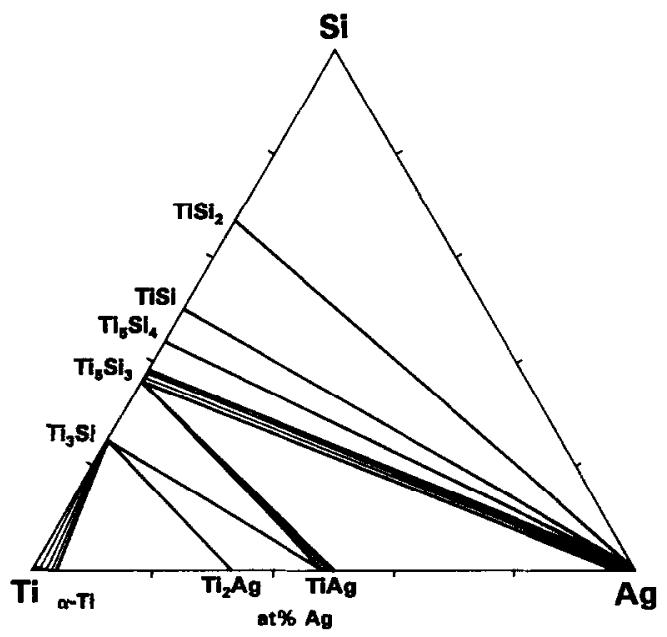

Fig. 13. Experimentally determined cross-section of the Ag-Ti-Si phase diagram at $1023 \mathrm{~K}$.

potential gradients across the diffusion zone. This process will eventually bring a $\mathrm{Ti}_{5} \mathrm{Si}_{4}$ layer into contact with $\mathrm{TiAg}$. Those phases connot be in equilibrium at $1023 \mathrm{~K}$, as dictated by the phase diagram, hence $\mathrm{Si}$-atoms diffusing through the reaction product layer will react at the $\mathrm{TiAg} / \mathrm{Ti}_{5} \mathrm{Si}_{4}$ interface: $5 \mathrm{TiAg}+4[\mathrm{Si}] \rightleftarrows \mathrm{Ti}_{5} \mathrm{Si}_{4}+5 \mathrm{Ag}$. As a result a continuous layer of silver will form, separating the $\mathrm{TiAg}$ and $\mathrm{Ti}_{5} \mathrm{Si}_{4}$ layers. The appearance of a silver layer creates a situation in which silicon atoms and titanium atoms can diffuse in opposite directions into an 'inert' Ag-solvent and react to form titanium silicides inside the silver. The subsequent evolution of the periodic layered structure of silver bands alternating with titanium silicide can be explained by adopting a line of reasoning analogous to that which explains the Liesegang phenomenon [27]. In general, Liesegang bands are known to occur in solids as a result of internal precipitation $[28,29]$. To our knowledge, however, this is the first observation of internal reaction in an in situ formed matrix.

\subsection{Periodic layer formation and the Kirkendall effect}

This section considers a number of solid state systems that also show periodic layer formation, like $\mathrm{Fe}_{3} \mathrm{Si} / \mathrm{Zn}$ [30], $\mathrm{Co}_{2} \mathrm{Si} / \mathrm{Zn}$ [31], $\mathrm{Ni}_{3} \mathrm{Si}_{2} / \mathrm{Zn}$ [32], $\mathrm{Ni}_{50} \mathrm{Co}_{20} \mathrm{Fe}_{30} / \mathrm{Mg}$ [33], $\mathrm{SiC} / \mathrm{Ni}$ [34] and $\mathrm{SiC} / \mathrm{Pt}$ 
[35]. However, we argue that the mechanism for the formation of those layers is different from the previous case.

All these systems exhibit the same type of phase diagrams and large differences in mobilities of the components inside the reaction zone. The common feature of the corresponding diffusion zones is that they consist of a periodic arrangement of two-phase bands. Periodic structures in which the bands coexist as single-phase layers are not observed.

The bands are embedded in a continuous matricx which is formed at the substrate/reaction zone interface. In the $\mathrm{Ni} / \mathrm{SiC}$ and $\mathrm{Pt} / \mathrm{SiC}$ systems the bands are formed by carbon which cannot diffuse intrinsically towards the metal in these diffusion couples because of the thermodynamic constraints as noted before [19]. Details on the periodic layer formation in the $\mathrm{Pt} / \mathrm{SiC}$ system can be found in [35]. More evidence that the periodic layer formation is not a Liesegang phenomenon can be seen from Fig. 14. A two-phase layer $\left(\delta-\mathrm{FeZn} n_{10}+\mathrm{FeSi}\right)$ is still

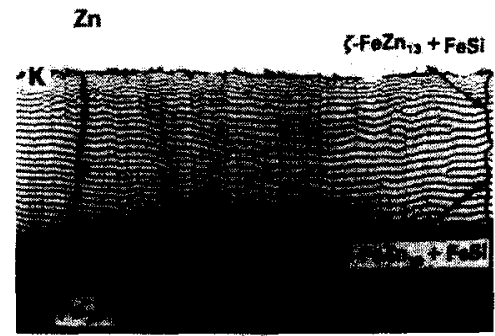

(a)

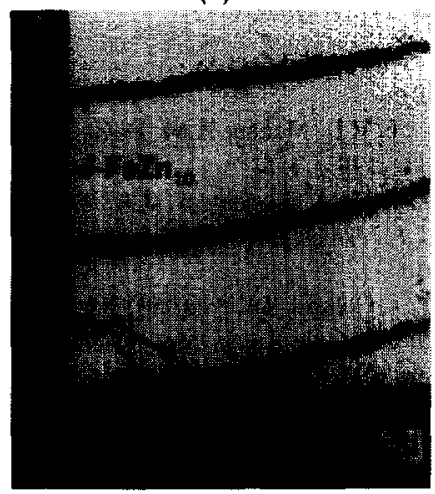

(b)

Fig. 14. BEI of the reaction zone in a $\mathrm{Fe}_{3} \mathrm{Si} / \mathrm{Zn}$ diffusion couple annealed in $\mathrm{He}$ for 121 at $663 \mathrm{~K}$; (a) general view; (b) magnified area close to the $\mathrm{Fe}_{3} \mathrm{Si}$ substrate. Letter $\mathrm{K}$ indicates position of the Kirkendall plane.

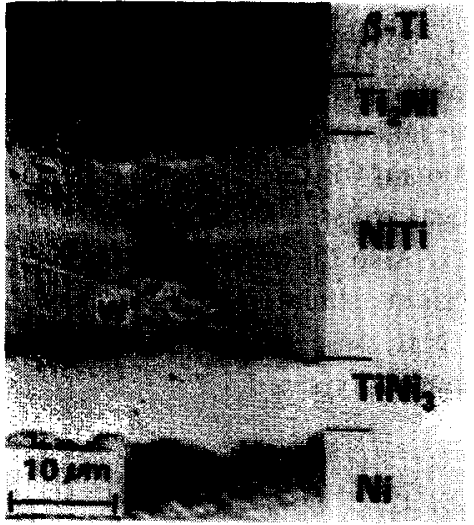

Fig. 15. The distortion and rupture of an initially circular tungsten wire ( $10 \mu \mathrm{m}$ diam.) placed between the $\mathrm{Ti}$ and $\mathrm{Ni}$ end-members of the diffusion couple after heat-treatment at $1073 \mathrm{~K}$ for $72 \mathrm{~h}$ in vacuum (optical micrograph).

present at the initial substrate when the previous one has been released. According to the Liesegang mechanism a new band is not formed until a critical supersaturation has been built up [36]. This is obviously not the case.

We link the appearance of a periodic layered structure to the large difference in mobilities of the components inside the diffusion zone and hence to a large vacancy flux in the direction of the fast component. If a relatively thick 'inert' marker ends up at the reaction interface between phases with opposite vacancy fluxes, actual rupture can occur, as shown by Bastin [37], for a multiphase $\mathrm{Ti} / \mathrm{Ni}$ diffusion couple (Fig. 15).

The FeSi bands may be considered as 'inert markers' formed in situ inside the diffusion zone and should drift into the direction of the faster component. By this mechanism the FeSi band close to the substrate can be split. The remaining FeSi-band at the substrate interface will then grow again until it reaches a critical thickness where disrupture takes place again, leading to the formation of a spatiotemporal pattern.

\section{Concluding remarks}

The reaction phenomena in multicomponent, multiphase systems can obviously be quite complex. However, by using the available thermodynamic data 
(especially phase diagrams and potential diagrams) and mobility data from the constituing binary systems, one often can predict, at least qualitatively, the composition and width of the diffusion zone. Many problems remain for the moment, especially the role of mechanical stresses which result from the diffusion process. Also the role of interface energies and non-equilibrium situations which have not been mentioned here pose some questions, especially in thin-film applications.

\section{Acknowledgments}

This investigation is supported by the Netherlands Foundation for Chemical Research (SON) with financial aid from the Netherlands Organization for Scientific Research (NWO).

\section{References}

[1] C. Wagner, Acta Met. 17 (1969) 99.

[2] J.H. Gülpen, A.A. Kodentsov and F.J.J. van Loo, Z. Metallkde. 86 (1995) 530.

[31 P. Nash and A. Nash, Bull. Alloy Phase Diagr. 8 (1987) 6.

[4] S. Prager, J. Chem. Phys. 21 (1953) 1344.

[5] J.H. Gülpen, A.A. Kodentsov and F.J.J. van Loo, in: Applications of Thermodynamics in the Synthesis and Processing of Materials, eds. P. Nash and B. Sundman (TMS, 1995) p. 127.

[6] J. Philibert, Defect and Diffusion Forum 66-69 (1989) 995.

[7] J.H. Guilpen, Reactive phase formation in the Ni-Si system, $\mathrm{PhD}$ Thesis (Eindhoven University of Technology, Eindhoven, the Netherlands, 1995).

[8] J.S. Kirkaldy and L.C. Brown, Can. Metallurgical Quart. 2 (1963) 89.

[9] J.B. Clark, Trans. Met. Soc. AIME 227 (1963) 1250.

[10] F.I.J. van Loo, G.F. Bastin and J.W.G.A. Vrolijk, Met. Trans. A 18 (1987) 801 .

[11] R.T. DeHoff, K.J. Anusavice and C.C. Wan, Met. Trans. 5 (1974) 1113.

[12] K.J. Rönkä, A.A. Kodentsov, P.J.J.T.P. van Loon, J.K. Kivilahti and F.J.J, van Loo, Met. Trans. A 27 (1996) 2229.

[13] L. Onsager, Annals NY Acad. Sci. 46 (1945) 241.

[14] L.S. Darken, in: Atom Movements, ed. J.H. Hollomon (ASM, Cleveland, 1951).
[15] M.A. Dayanandu and C.W. Kim, Met. Trans. A 10 (1979) 1333.

[16] A. Jansson, TRITA-MAC-0340 (Mater. Res. Cent., the Royal Inst. of Technol., Stockholm, 1987).

[17] Landolt-Börnstein, Diffusion in Solid Metals and Alloys, Vol. 26, ed. H. Mehrer (Springer Verlag, Berlin, 1990).

[18] R.A. Rapp, E. Ezis and G.Y. Yurek, Met. Trans. 4 (1973) 1283.

[19] F.J.J. van Loo, Prog. Solid State Chem. 20 (1990) 47.

[20] X.L. Li, R. Hillel, F. Teyssandier, S.K. Choi and F.J.J. van Loo, Acta Metal. Mater. 40 (1992) 3149.

[21] J.I. Goldstein, S.K. Choi, F.J.J. van Loo, G.F. Bastin and R. Metselaar, J. Am. Ceram. Soc. 78 (1995) 313.

[22] W. Wakelkamp, Diffusion and phase relations in the systems $\mathrm{Ti}-\mathrm{Si}-\mathrm{C}$ and $\mathrm{Ti}-\mathrm{Si}-\mathrm{N}, \mathrm{PhD}$ Thesis (Eindhoven University of Technology, Eindhoven, The Netherlands, 1991).

[23] E. Heikinheimo, A.A. Kodentsov, J.A. van Beek, J.T. Klomp and F.J.J. van Loo, Acta Metal. Mater. Suppl. 40 (1992) S111.

[24] A.A. Kodentsov, I.K. Kivilahti and F.J.J. van Loo, HighTemp. Sci. Mater. 34 (1995) 137.

[25] A.A. Kodentsov, J.H. Gölpen, C. Cserhati, J.K. Kivilahti and F.J.J. van Loo, Met. Trans. A 27 (1996) 59.

[26] T.B. Massalski, J.I. Murray, L.H. Bennett and H. Baker, Eds., Binary Alloy Phase Diagrams (American Society for Metals, 1986).

[27] M.R. Rijnders, J.A. van Beek, A.A. Kodentsov, and F.J.J. van Loo, Z. Metallkde. 87 (1996) 733.

[28] V.A. van Rooijen, E.W. van Royen, J. Vrijen and S. Radelaar, Acta Met. 23 (1975) 987.

[29] H. Schmalzried and T. Frick, Ber. Bunsenges. Phys. Chem. 99 (1995) 914

[30] K. Osinski, A.W. Vriend, G.F. Bastin and F.J.J. van Loo, Z. Metallkde. 73 (1982) 258.

[31] M.R. Rijnders and F.J.J. van Loo, Scripta Metal. Mater. 32 (1995) 1931

[32] M.R. Rijnders, A.A. Kodentsov, C. Cerháti, J. van den Akker and F.J.J. van Loo, Defect and Diffusion Forum 129/130 (1996) 253.

[33] S.F. Dunaev and S.A. Zver'kov, J. Less-Comm. Metals 153 (1989) 143

[34] M.R. Jackson, R.L. Mehan, A.M. Davis and E.L. Hall, Met. Trans. A 14 (1983) 355.

[35] M.R. Rijnders, A.A. Kodentsov, J.A. van Beek, J. van den Akker and F.J.J. van Loo, Solid State Ionics 95 (1997) 51 (this issue).

[36] C. Wagner, J. Colloid Sci. 5 (1950) 85.

[37] G.F. Bastin and G.D. Rieck, Met. Trans. 5 (1974) 1817.

[38] L. Kaufman, CALPHAD 3 (1979) 45. 